Annals of Glaciology $3 \quad 1982$

() International Glaciological Society

\title{
RESULTS FROM THE AMERY ICE SHELF PROJECT
}

\author{
by
}

\author{
W. F. Budd
}

(Meteorology Department, University of Melbourne, Parkville, Victoria 3052, Australia)

\section{J. Corry}

(c/o Country Roads Board, State Government of Victoria, 60 Denmark Street, Kew, Victoria 3101, Australia)

and T. H. Jacka

(Antarctic Division, Kingston, Tasmania 7150, Australia)

\section{ABSTRACT}

The major results from a comprehensive study of the Amery Ice Shelf are presented, following the work of a wintering expedition in 1968 and supplemented by further measurements during the suminer seasons of 1969 to 1971. The programme included ice-core drilling, oversnow surveys for ice movement and optical levelling, ice-thickness sounding, and measurements of snow accumulation. The new data obtained provide the basis for a more accurate assessment of the mass balance and dynamics of the ice shelf than was possible from the earlier surveys.

The results indicate a substantial growth of basal ice under the ice shelf inland where the ice thickness is greater than $450 \mathrm{~m}$. Further towards the ice front the high strain thinning is approximately balanced by the horizontal ice advection.

The velocity distribution over the ice shelf is primarily governed by a substantial surface slope towards the ice front and high restraining shear stress along the sides.

\section{EXPEDITION ACTIVITIES}

The preliminary surveys of the Amery Ice Shelf, carried out between 1962 and 1965 , as described by Budd (1966) and Budd and others (1967) were accomplished by extensive oversnow traverses from Mawson during the spring-summer seasons. In order to make a more complete study of the ice shelf, it was proposed that a small group should spend a whole year there in order to undertake a comprehensive programme.

The progranme $p l a n$ was devised by $W F$ Budd and $U$ Radok, and was accepted and undertaken by the Antarctic Division as part of the Australian National Antarctic Research Expeditions (ANARE). The four-man wintering party consisted of $M J$ Corry (surveyor and leader), A H F Nichols (electronics engineer), N J Collins (senior diesel mechanic), and $J R$ Sansom (doctor).

The progranme involved the establishment of a caravan-complex living base at G1 (see Fig.1) by oversnow traverse from Sandefjord Bay, where the ship could land the party. A thermal drill bought from the US Army Cold Regions Research and Engineering Laboratory (CRREL) was al so transported oversnow to Gl and was used to core-dri $11310 \mathrm{~m}$ into the ice shelf during the winter.
A micrometeorology-climatology station was established at G1 in March 1968 and was operated until December 1968. Further meteorological measurements were taken over the ice shelf in the course of the summer traverses.

During spring and summer, a number of survey traverses were undertaken, using electronic distancemeasuring equipment and theodolites, over the route shown in Figure 1 in order to establish ice-movenent markers longitudinally down the ice shelf (T4 to A509) and two cross-profiles (Sandefjord Bay to Depot $E$ and Beaver Lake via T3, G3, and T2 to Manning Nunataks). This same route was then accurately levelled, using an automatic optical level with staffs and tying to sea-level at Sandefjord Bay and Beaver Lake, which is tidal.

During the following summer (1969-70), the complete traverse was resurveyed to determine the movement of the ice at all markers and to measure the snow accumulation. The previous markers established by Budd in 1964 at $\mathrm{G} 1, \mathrm{G} 2$, and G3 were also reneasured.

A radio echo-sounder was taken along the oversnow route and was used to measure the ice thickness except between GI and Depot E. Further radio ice-thickness sounding was carried out from the air during 1971-74, as discussed by Morgan and Budd (1975). The longitudinal traverse-route thickness profile is shown in Figure 2.

The bore hole at $G 1$ was used to measure the temperatures in the ice shelf as shown in Figure 3 . The bulk of the ice core was returned to Australia for a variety of analyses as indicated below.

The analyses of the data include determination of ice velocities, strain-rates, particle paths, mass balance, numerical modelling of temperatures, and analysis of stress and strain-rates. A complete compilation of the results is due to be produced as an ANARE report. The present paper is aisned at summarizing the major results.

\section{ICE-CORE AND BORE-HOLE RESULTS}

The $180 / 160$ oxygen isotope ratios neasured by Morgan (1972) indicated that the glacier ice at G1 occurs from 70 to $270 \mathrm{~m}$ depth. Below that, the ice is of oceanic origin, while the surface material is formed from snow accumulation on the ice shelf. The 


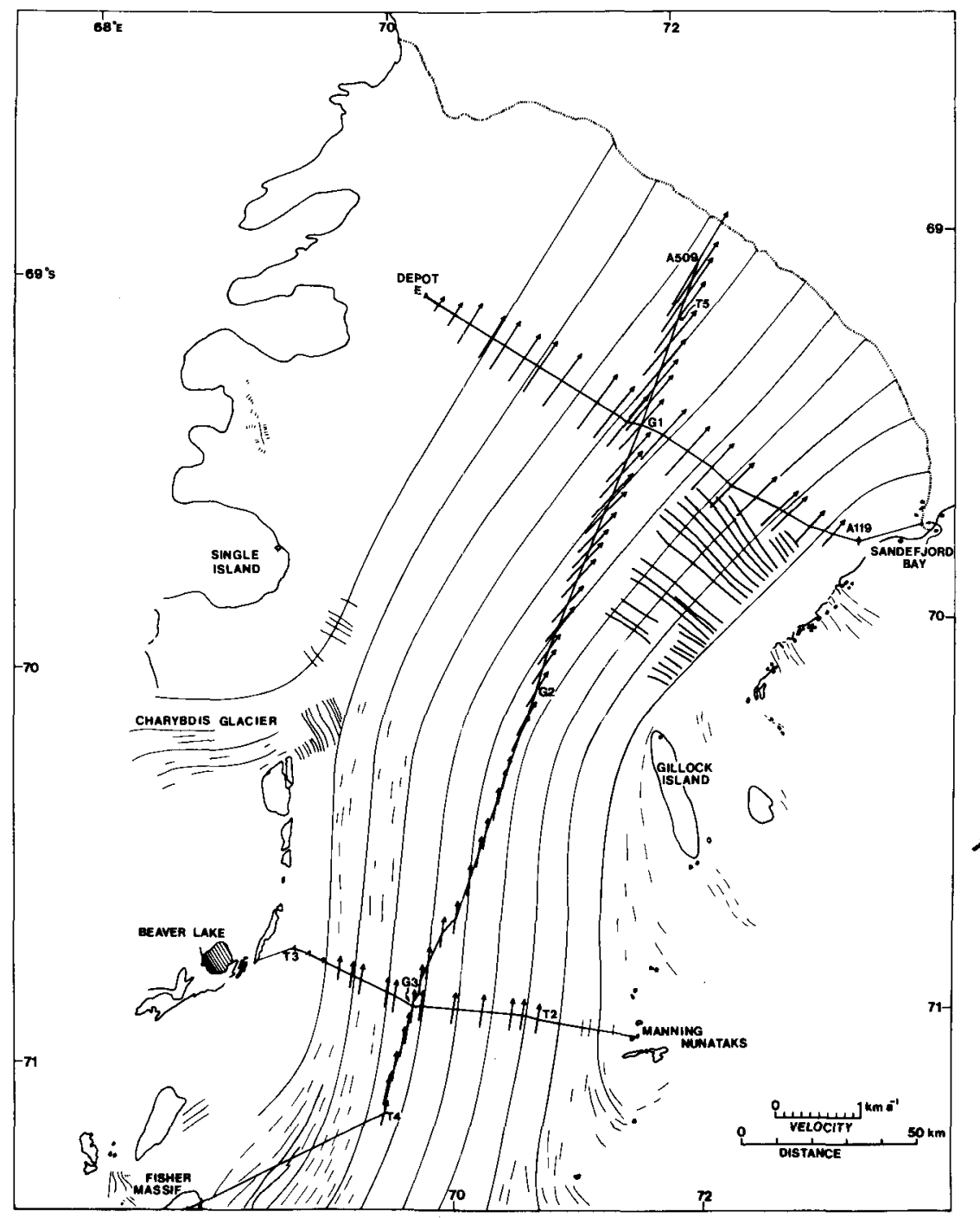

Fig.1. The Amery Ice Shelf Project traverse routes are shown together with ice-movement vectors at the marker poles and estimated flow lines derived from the vectors and satellite image features.

salinity measurements also are in agreement with that picture.

The ice crystallography as determined by Wakahama and Matsuda also reflects the histories of these three different types of fce (cf. Budd 1972, Wakahama 1974).

The results of these studies agree well with the computation of particle paths as described below and as illustrated in Figure 2 .

The bore-hole temperatures have been analysed in detail by $\mathrm{N} W$ Young, by numerical modelling of the ice flow and temperatures through the central flow line along the ice shelf. The temperatures at $10 \mathrm{~m}$ depth along the surface used in the modelling were as described by Budd (1966). A close match to the observed temperature-depth profile is obtained for a basal-ice growth rate of $0.6 \mathrm{~m} \mathrm{a}^{-1}$. It is shown bel ow that the particle-path modelling gives a similar average basal growth rate up-stream of G1.

\section{ICE-MOVEMENT SURVEYS}

The positions of the markers shown by the arrows in Figure 1 were obtained by a reduction of the survey tied to the fixed points on rock at Sandefjord Bay, Beaver Lake, Manning Nunataks, and Fisher Massif. The effect of the movement of the ice during the survey was removed by a series of iterations after an initial velocity was derived from the second survey.
The resultant velocity vectors are shown in Figure 1. I dealized flow lines have been drawn in as indicated by features from Landsat satellite imagery and measured velocity vectors. Close agreement of the flow directions is obtained, clarifying the flow

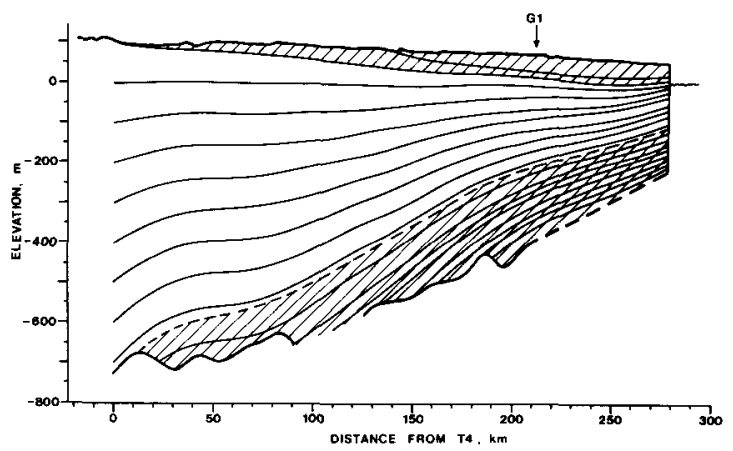

Fig.2. The surface and base profiles of the Amery Ice Shelf along the central flow line are shown with particle paths calculated from the observed ice deformation. The hatched regions indicate the accumulated snow and ice on the upper and lower surfaces of the ice shelf. 
from the various ice streams and around obstacle features such as Gillock Island. Crevasse patterns are prominent in regions both of high shear and high tension.

From the velocity data, strain-rates in the longitudinal and transverse directions $\left(\dot{\varepsilon}_{x}\right.$ and $\left.\dot{\varepsilon}_{y}\right)$ have been calculated along the central flow region, and lateral shear strain-rates $\left(\dot{\varepsilon}_{x y}\right)$ across the ice shelf for the two lateral profles have also been computed. The divergence of the flow lines, combined with the forward velocity, provides an additional check on the transverse strain-rates.

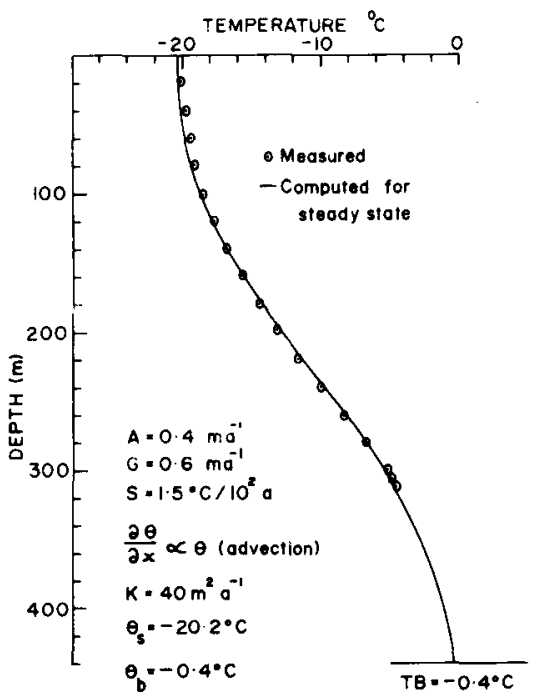

Fig.3. The measured temperature profile in the G1 bore hole is shown $(\theta)$ with the profile computed by $\mathrm{N} W$ Young for a basal growth rate $G$ of $0.6 \mathrm{~m} \mathrm{a}-1$. other parameters used in the computation include: surface accumulation rate $A$, rate of change of surface temperature along ice shelf $S$, thermal diffusivity $k$. Although ice growth was obtained up-stream, melting was found to start near G1 so a basal temperature of $-0.4{ }^{\circ} \mathrm{C}$ was used.
The results of these calculations for the central flow region are illustrated in Figure 4 . The velocity and shear across the ice shelf are illustrated in Figures 7 and 8 .

\section{ELEVATION AND ICE THICKNESS}

The surface elevation over the traverse route has been obtained quite accurately from the optical levelling. The relative error over several kilometres is within $10 \mathrm{~mm}$, whilst, over the whole net, the ties to sea-level at Sandefjord Bay, Beaver Lake, and over the ice cliff of the front north of A509 indicate a cumulative error less than $0.5 \mathrm{~m}$. These elevation data provide the basis for the ice-surface profiles shown in Figures 2 and 6 . Except for a slight rise towards the centre, the surface is comparatively flat across the ice shelf but slopes downwards substantially from Lambert Glacier, just south of $\mathrm{T} 4$ at $\sim 100 \mathrm{~m}$ elevation, to $45 \mathrm{~m}$ at the ice front over a distance of about $300 \mathrm{~km}$. Although there are irregularities to this average slope, the large-scale trend of slope along the centre flow line is fairly uniform as shown by the elevations given in the accompanying table. This average slope is $\sim 1.8 \times 10^{-4}$.

The ice thickness was measured along the traverse route by A Foster in 1969 and 1970, and later, in part from an aircraft, by $A$ Foster and $V$ Morgan, following the same route. The results have been plotted in Figures 2 and 6 to show the broad-scale features. On the small scale, of the order of 1 to $5 \mathrm{~km}$, surface and basal fluctuations predominate, and are apparentiy related, but on the larger scale relatively uniform thickness occurs across the floating part of the ice shelf. From Lambert Glacier, a slight thickening occurs after floating followed by a gradual thinning towards the ice front. The elevation:ice thickness ratio varies from 0.160 near the ice front to 0.113 near $T 4$. This change is primarily associated with changing density due to snow cover along the ice shelf as shown in Figure 2.

The grounding-floating transition takes place about $3 \mathrm{~km}$ south of T4 where a maximum in the surface slope occurs. The surface elevation drops from 100 to $86 \mathrm{~m}$ in $19 \mathrm{~km}$ with only a small change in ice thickness which is about $800 \mathrm{~m}$ there. This region is an
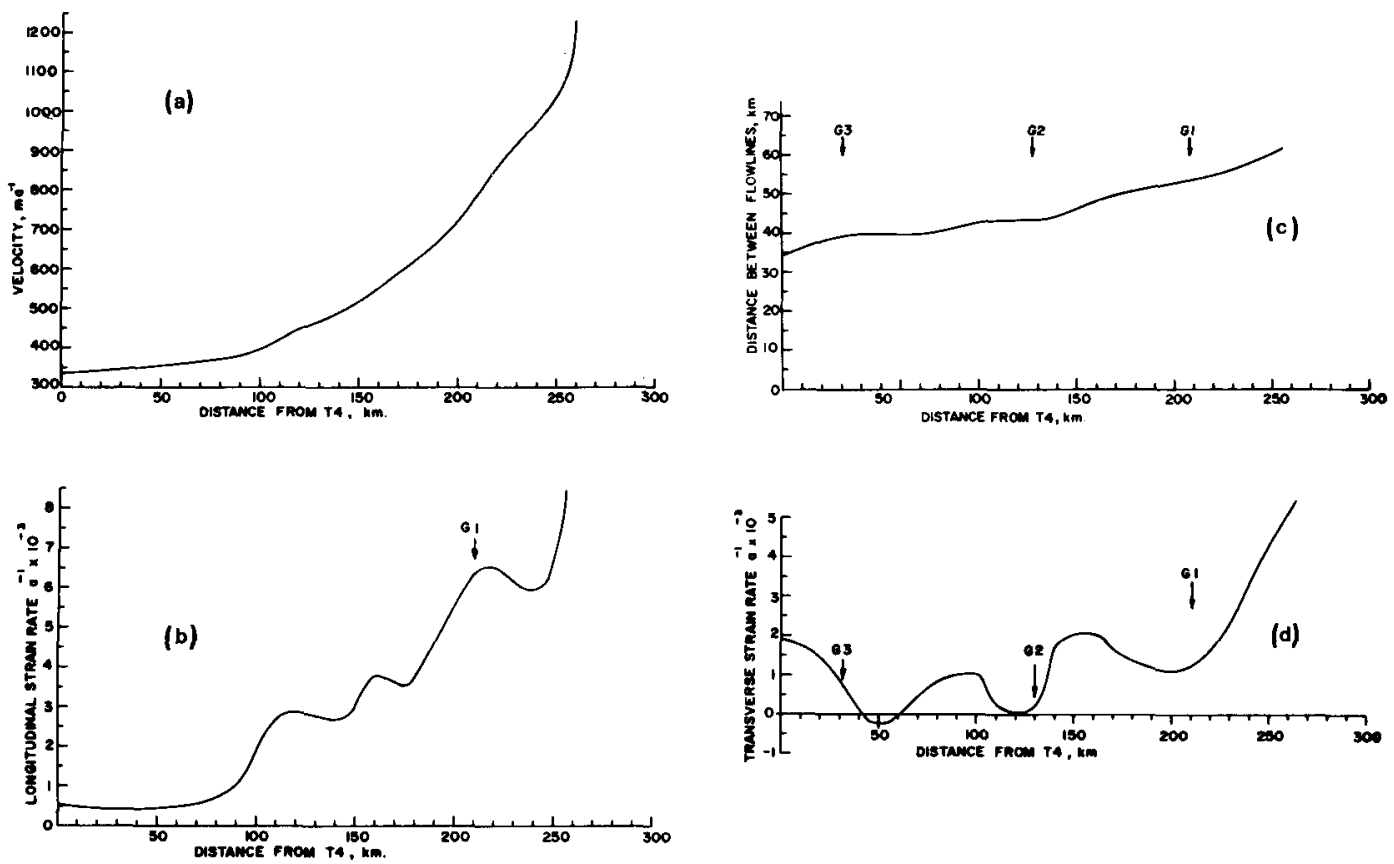

Fig.4. Various features along the ice-shelf central flow band are shown as follows: (a) centre-line velocity, (b) longitudinal strain-rate, (c) flow-1ine divergence rate, and (d) transverse strain-rate. 


\begin{abstract}
Distance from
ice front $(\mathrm{km})$
\end{abstract}

Elevation $(\mathrm{m})$

\begin{abstract}
$0 \quad 20 \quad 40 \quad 60$
$45 \quad 51 \quad 56$
\end{abstract}

60
100

71

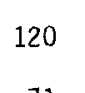

120
140

71

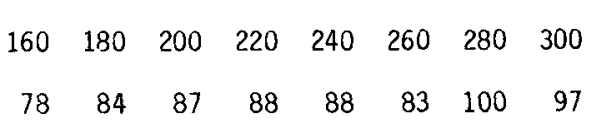

ablation area and is characterized by a high-density "blue-ice" surface. Further north, the snow accumulation again increases the elevation: ice thickness ratio such that by $G 1$ the elevation is $64 \mathrm{~m}$ for $\sim 450 \mathrm{~m}$ ice thickness. The mean density implied of 0.89 checks well with the density measurements from the G1 ice core. The numerous sma11-scale undulations on the surface with wavelengths of several times the ice thickness appear to be caused by minor slight groundings. It is expected that these could cause only ininor impediments to the flow; otherwise, largerscale slope deviations would be generated.

\section{SNOW ACCUMULATION}

Direct measurenents of the snow-accumulation rate over the traverse route stake network are available froin 1953 to 1964,1964 to 1968 , and 1968 to 1969. Some further data are available from 1962 to 1963 and 1969 to 1970 . The weighted mean net snow accumulation varies fairly smoothly, from $1.2 \mathrm{~m} \mathrm{a}^{-1}$ of snow ( 0.45 in of water equivalent) near the ice front to zero on Lambert Glacier $\sim 300 \mathrm{~km}$ inland. Mean values over the ice shelf are given in Table II and are also shown in Figure 5. Variation across the ice shelf is rather sinall except for the sinall-scale topographic influences.

6. PARTICLE PATHS AND BASAL MASS EXCHANGE

The vertical strain $\dot{\varepsilon}_{z}$ has been calculated along the central flow band from

$$
\dot{\varepsilon}_{z}=-\left(\dot{\varepsilon}_{x}+\dot{\varepsilon}_{y}\right) \text {. }
$$

Together with the longitudinal velocity $V$ and ice thickness $Z$, this allows the relative particle spacings in a vertical column to be calculated. The surface elevation and snow-accumulation rate $A$ provide the surface flux and the control for the particle paths. At the base, the difference between the basal particle paths and the measured base provide the basal growth or melt rate, as shown in Figure 2. The actual thickness of basal grown ice is less than the accumulated growth rate because of the thinning due to the strain. The actual computed basal-ice growth rate is shown in Figure 5. The accumulated basal-ice growth obtained from the particle paths as shown in Figure 2 agrees well with that obtained in the Gl bore hole, and, with the allowance made for strain, confirms the computed basal growth rates.

The net result shows initially a substantial growth rate after the ice becomes afloat with the accumulated ice increasing to a maximum thickness of about $200 \mathrm{~m}$ near $\mathrm{G} 1$ where the ice-base depth is about $400 \mathrm{~m}$. Further north, the increasing rate of strain thinning causes a reduction in the thickness of the ice of oceanic origin to about $100 \mathrm{~m}$ at the ice front.

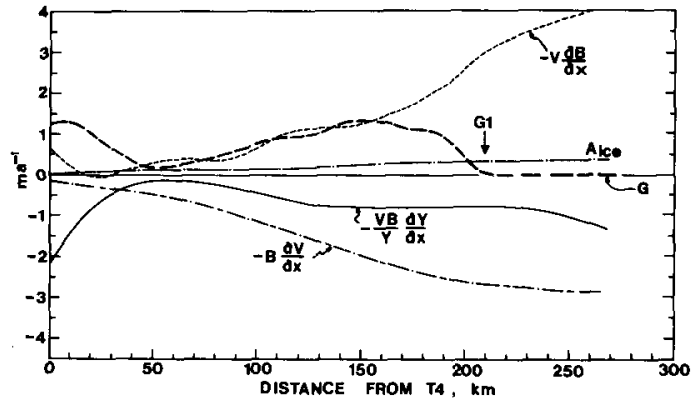

Fig.5. Mass-balance components. The following terms of the mass-balance equation are shown for the iceshelf central flow band: surface accumulation rate $A$, basal growth rate $\hat{a}$, horizontal advection $V \frac{\partial B}{\partial x}$, longitudinal strain thinning $B \frac{\partial V}{\partial x}$, and $\frac{\partial}{\partial x}$ strain thinning $\frac{V B}{Y} \frac{\partial Y}{\partial X}$.

7. CONTINUITY AND MASS BALANCE

The mass balance for the central flow band has been examined from the continuity equation

$$
\frac{\partial Z}{\partial t}=A-M-\frac{1}{\bar{Y}} \frac{\partial V Z Y}{\partial X},
$$

where $Z$ is the ice thickness at distance $x$ along the flow line at time $t, A$ is the surface accumulation rate, $M$ is the basal melt rate, $V$ is the forward velocity, and $Y$ is the distance between flow lines. It is of interest to examine the individual terms of the continuity equation as follows:

$$
\frac{\partial Z}{\partial t}=A-M-V \frac{\partial Z}{\partial x}-Z \frac{\partial V}{\partial x}-\frac{V Z}{Y} \frac{\partial Y}{\partial x} .
$$

The terms $Z \frac{\partial V}{\partial x}$ and $\frac{V Z}{Y} \frac{\partial Y}{\partial x}$ represent the contributions to the thinning due to longitudinal and transverse strain. The total vertical strain-rate thinning is given by

$$
Z \dot{\varepsilon}_{Z}=-Z\left(\dot{\varepsilon}_{x}+\dot{\varepsilon}_{y}\right)=-Z\left(\frac{\partial V}{\partial x}+\frac{V}{Y} \frac{\partial Y}{\partial x}\right) \cdot
$$

Figure 5 shows the variation of these various terins along the ice shelf, except that, in order to deal with volume or mass units allowing for the lower density of the surface firn, the parameter $B$ has been introduced to replace $Z$ such that $B$ is the equivalent thickness of a column of the density of ice.

TABLE II. MEAN ACCUMULATION RATE 1962 TO 1970

$\begin{array}{ccccccccc}\begin{array}{c}\text { Distance from } \\ \text { ice front }(\mathrm{km})\end{array} & 0 & 40 & 80 & 120 & 160 & 200 & 240 & 280 \\ \text { Snow }\left(\mathrm{m} \mathrm{a}^{-1}\right) & 1.20 & 1.07 & 0.92 & 0.82 & 0.58 & 0.42 & 0.25 & 0.12 \\ \quad\left(\mathrm{ilg} \mathrm{\textrm {m } ^ { - 2 } )}\right. & 0.44 & 0.40 & 0.34 & 0.30 & 0.21 & 1.16 & 0.09 & 0.04\end{array}$


Along the ice sheif, the strain and advection terms are large compared to the surface-accumulation rate. The basal growth rate, which has been computed on the assumption of steady state, is also large compared to the surface-accumulation rate out as far as G1, after which the basal mass flux appears to be close to zero.

Initially, after becoming afloat, the basal growth rate is large and is approximately balanced by the strain thinning. Further towards the ice front, the ice basal slope becomes steeper, and, together with the higher velocity, causes the horjzontal advection term $V \frac{\partial z}{\partial x}$ to approximately balance $\frac{\partial z}{\partial x}$ the large strain-rate thinning.

\section{DYNAMICS OF THE ICE SHELF}

The major problem of ice-shelf dynamics is to determine the velocity distribution from the iceshelf geometry and boundary conditions, cf. Budd (1966 and 1969), Thomas (1973[a] and [b]). Since the earlier study by Budd (1966) the ice-surface elevation and ice thickness have been obtained accurately. The major difference from the results of the earlier, less accurate data is that the surface slope is larger and more uniform along the ice shelf. Furthermore, it is now quite clear how the velocity varies across the ice sheif (at least near G1 and G3) and where the transition occurs between fast flowing ice and the relatively stagnant ice-shelf boundary region.

The form of the lateral velocity profiles is

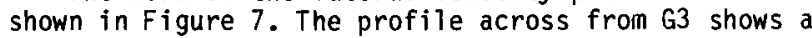
typical high power-law flow regime

$$
v_{y} \propto y^{n+1}
$$

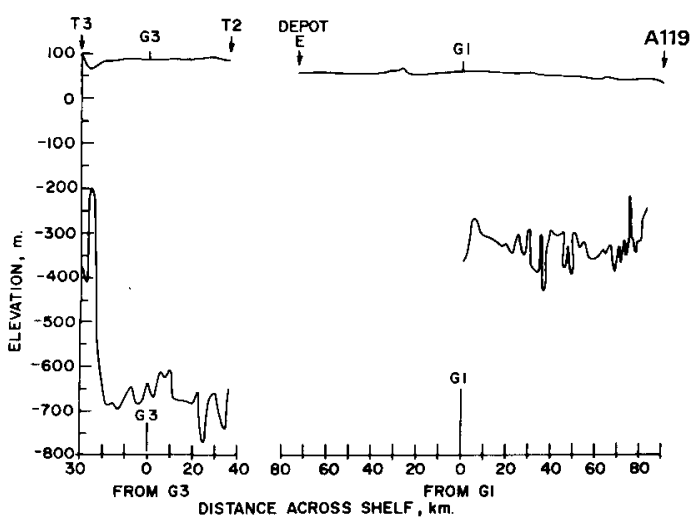

Fig.6. Transverse profiles of the ice surface and base across the ice shelf are shown for the traverse routes of Figure 1 for (a) T3, G3, and T2, and (b) Depot $E$ through G1 to A119 near Sandefjord Bay.

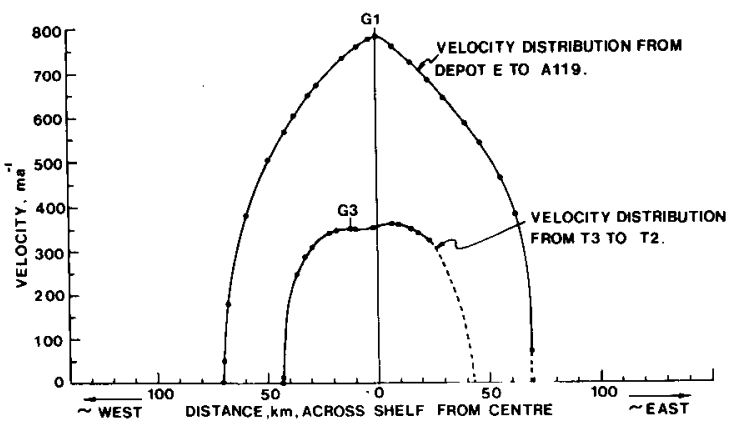

Fig.7. The measured velocity profiles across the ice shelf through $G 1$ and $G 3$ are shown as a function of distance perpendicular to the flow direction. where $V_{y}$ is the velocity difference from the centreline velocity, $y$ is the distance from the centre line, $n \approx 3$ is the index of the power law for ice flow.

The profile across from Gl approaches the same form of relation near the edge, but towards the centre the dominance of the longitudinal strain-rate results in an apparent decrease in the $n$ value or a higher velocity due to the addition of the longitudinal stress to the octahedral stress.

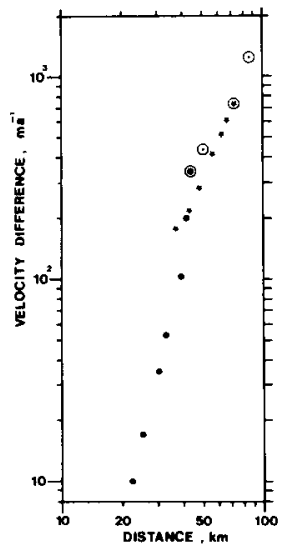

Fig.8. The velocity difference from the centre-line velocity is shown as a function of distance from the centre line (on log-log coordinates) for the southern (.) and northern (*) profiles. Also shown is the centre-line velocity as a function of half-width $(Y)$ along the ice shelf.

Figure 8 shows the variation of the centre-line velocity over the ice shelf with distance of the centre line from the edge superimposed upon the velocity differences across the ice shelf at $G 1$ and G3. Near the edges, the shear strain-rates are large and the longitudinal strain-rates are small. Therefore, to a first approximation, a reasonable fit to the velocity distribution can be obtained from

$$
\frac{V}{Y}=K \tau_{Y}^{n}
$$

where $Y$ is the half-width, $K$ is a flow-law parameter dependent mainly on the ice temperature and crystal fabrics $\left(K \sim 1.6 \times 10^{-2} \operatorname{bar}^{-3} \mathrm{a}^{-1}\right)$, and

$$
\tau_{Y}=\rho g \bar{\alpha} \gamma
$$

with $\rho$ the ice density, $g$ the gravitation acceleration, and $\bar{\alpha}$ the large-scale mean surface slope.

It is interesting to note that the relation shown in Equation (5) is remarkably sinilar to the relation

$$
\frac{v}{Z}=k \tau_{b}^{n} \quad\left(k \sim 2.5 \times 10^{-2} \operatorname{bar}^{-4} a^{-1}\right)
$$

obtained for the surface velocity of cold ice sheets as given by Budd and Smith (1981), and also the relation for horizontal shear strain-rate versus depth in the bore hole near Cape Folger given by RussellHead and Budd (1979). The higher value of $n$ in the relation obtained by Budd and Smith is presumed to be related to effects of changing average basal temperature or crystallographic fabrics along the flow 1 ine.

It may be noted that in all cases the field strain-rates tend to be $\sim 4$ to 5 times higher than for the corresponding randomly oriented polycrystalline ice, suggesting similar strong fabric effects. In the case of ice-sheif flow, it could be expected that the relevant fabrics would be a strong concentration of horizontal c-axes perpendicular to the flow near the edges of the ice shelf. 
The relation (5), with the constants as given or adjusted for the temperature, could be used for first-order modelling of the ice dynamics. For high longitudinal strain-rates, an additional term is needed, given by Budd (1969) as follows:

$$
\frac{\partial \bar{Z} \bar{\sigma}_{x}^{\prime}}{\partial x}=-(1 / 2)(\rho g \alpha \bar{Z})-\tau_{Y},
$$

where $\sigma_{x}{ }^{\prime}$ is the longitudinal stress deviator and the bars indicate the mean over the cross-section. Here the lateral divergence and transverse extensive strain-rates are neglected, but can be included if they are substantial. For the Amery Ice Shelf, although the longitudinal strain-rate increases rapidly towards the ice front, the ice thickness decreases, making the term on the left of Equation (8) smal1. This means that the approximate equality of the terms on the right-hand side is maintained reasonably closely. The inclusion of the lateral divergence, the changing width, and the variation of ice temperature along the ice shelf only slightly affect the longi tudinal stress gradient.

A further consequence of the presence of a substantial longitudinal stress is that both the longitudinal and shear stresses and strain-rates are involved in the expression for the octahedral shear stress- and strain-rates. This needs to be considered when relating the transverse shear stress- and strainrates. However, we note that the longitudinal strainrates also tend to zero with the velocity towards the sides of the ice shelf. If the longitudinal stress gradient is neglected, it appears that the value of the transverse shear stress at the edge $\tau$ increases along the ice shelf towards the ice front ${ }^{Y}$ from $\sim 0.56$ bar across from $G 3$ to $\sim 1.1$ bar across from $T 5$. This high shear zone is accompanied by high shear velocity gradients $\left(\frac{\partial V}{\partial y}\right)$, reaching values of $\sim 5 \times 10^{-2} \mathrm{a}^{-1}$ over the last few kilometres towards the edge.

Towards the ice front, the removal of the bounds of the ice shelf could be expected to result in a thinning governed by the relation for free-floating ice obtained by Weertman (1957). For the case of the Amery Ice Shelf, the maximum strain thinning approaches $1.6 \% \mathrm{a}^{-1}$ near the ice front.

\section{DISCUSSION AND CONCLUSIONS}

A number of important results have emerged from the study of the Amery Ice Shelf, which are worth emphasizing here. 1. The surface of the ice shelf has a substantial slope downwards towards the ice front which is comparatively uniform on the large scale over the ice shelf. 2. This surface slope provides the prinary driving force for the high centre-line velocities, which reach over $1200 \mathrm{~m} \mathrm{a}^{-1}$ near the ice front. 3. The 1ateral shear velocity gradients near the sides are generally high $\left(\sim 5 \% \mathrm{a}^{-1}\right)$ compared to the longitudinal velocity gradient along the ice shelf, which nevertheless reaches $\sim 1 \% a^{-1}$ near the ice front. 4. The dynamics of the ice shelf can be modelled reasonably to a first approximation from the lateral shear stress and strain-rates. only a small stress correction for longi tudinal stress gradients and thickness gradient towards the ice front needs to be made. 5. Substantial growth of ice occurs under the ice shelf up to about $70 \mathrm{~km}$ inland of the ice front. Further towards the ice front, the basal mass flux seems to be small. 6 . The high strain-rate thinning, reaching $\sim 1.6 \% \mathrm{a}^{-1}$, seems to be the major limiting factor to the forward growth of the ice shelf rather than melting. This thinning reduces the thickness as the ice shelf moves northwards such that, periodically, extensive sections are removed by the calving of large icebergs.

\section{ACKNOWLEDGEMENTS}

The Amery I ce Shelf Project would not have been possible without the enthusiastic support provided by many members of Antarctic Division and ANARE. In particular, Dr P G Law, Mr D F Styles, and Mr P $H$ Sulzberger contributed greatly to the organization and execution of the project. For the present paper, the contribution from the other members of the wintering party, MrN J Collins, MrAHF Nichols, and Dr J R Sansom, is particularly appreciated.

The authors are also grateful for the provision of ice-thickness data by Mr A Foster and Mr VI Morgan, results of ice-core analyses by Drs G Wakahama and Matsuda, and the temperature modelling results of Mr N W Young.

\section{REFERENCES}

Budd W F 1966 The dynamics of the Amery Ice Shelf. Journal of GLaciology 6(5): 335-358

Budd W F 1969 The dynamics of ice masses. ANARE Scientific Reporte Ser A (IV) Glaciology (Publication 108)

Budd W F 1972 The development of crystal orientation fabrics in moving ice. Zeitschrift für Gletscherkunde und Glazialgeologie 8(1-2): 65105

Budd W F, Smith I N 1981 The growth and retreat of ice sheets in response to orbital radiation changes. International Association of HydroLogical Sciences Publication 131 (Symposium at Canberra 1979 - Sea level, ice and climatic change): $369-409$

Budd W F, Landon-Smith I H, Wishart E R 1967 The Amery Ice Shelf. In Oura H (ed) Physics of snow and ice: International conference on low temperature science...1966...Proceedings 1(2). Sapporo, Hokkaido University. Institute of Low Temperature Science: $447-467$

Morgan V I 1972 Oxygen isotope evidence for bottom freezing on the Amery Ice Shelf. Nature 238(5364): 393-394

Morgan V I, Budd W F 1975 Radio-echo sounding of the Lambert Glacier basin. Journal of Glaciology 15(73): 103-111

Russel1-Head D S, Budd W F 1979 Ice-sheet flow properties derived from bore-hole shear measurements combined with ice-core studies. Journal of Glaciology 24(90): 117-130

Thomas R H 1973[a] The creep of ice shelves: theory. Journal of Glaciology 12(64): 45-53

Thomas R H 1973[b] The creep of ice shelves: interpretation of observed behaviour. Journat of Glaciology 12(64): 55-70

Wakahama G 1974 Nankyoku Amerī-tanagöri, Ūịrukusu-hyōkyū oyobi Forugā-misaki no shinsōgori no kozo-soshiki ni tsvite [On the structure and texture of deep ice cores from Amery Ice Shelf, Wilkes Dome and Cape Folger, Antarctica]. In Kuroiwa D (ed) Kyokuchi hyoshogori no butsuriteki kagakuteki kenkyu [Physical and chemical studies on ice from glaciers and ice sheets]. Sapporo, Hokkaido University, Institute of Low Temperature Science: 99-108

Weertman J 1957 Deformation of floating ice shelves. Joumal of Glaciology 3(21): 38-42 